\title{
Non-Invasive Ventilation in Preventing Intubation and Reintubation in The Intensive Care Unit of Pediatrics Zagazig University Hospital Mohamed Mohamed Abdel-Rahim*1, Tarek Abdel-Rahman Mohamed Attia ${ }^{2}$, Dalia Abdel-Latif Abdel-Rahman ${ }^{2}$ \\ ${ }^{1}$ Resident of Pediatrics, Maghagha General Hospital, Minya, Egypt. \\ ${ }^{2}$ Pediatric Department, Faculty of Medicine, Zagazig University, Sharkia, Egypt. \\ *Corresponding Author: Mohamed Mohamed Abdel-Rahim, Mobile: +20 1068161730, Email: mohamedrahiem22@gmail.com
}

\begin{abstract}
Background: Non-invasive ventilation (NIV) refers to methods of respiratory assistance without an indwelling endotracheal tube. Objectives: To evaluate the efficacy, identify possible predictors for the success of NIV in preventing intubation and re-intubation, and to determine the characteristics, and outcomes associated with NIV therapy in Pediatric intensive care units (PICUs) settings.

Patients and Methods: A clinical trial study was conducted at the Pediatric Intensive Care Units, Children Hospital, Zagazig University and Al-Ahrar Educational Hospital on 60 patients divided equally into two groups; group A with NIV as the first line and group B with NIV after extubation. Patients were followed up till weaning.

Results: Male constituted a larger percentage with both groups. One-sixth and $20 \%$ of patients within group A and $B$ respectively had failed to wean. There is a statistically significant difference between the outcome of weaning among group A and all of PIM-2 score, PIM-2 percent, and NIV duration. While the relation is significant between the outcome of weaning among group B and patients' age, body weight, and NIV duration. Increasing NIV duration significantly predicts weaning success in group A while increasing body weight predicts it in group B.

Conclusion: Non-invasive ventilation as the first line of treatment in acute respiratory failure provides significant avoidance of intubation and lowers the incidence and risk of complications. Non-invasive ventilation if considered after weaning of invasive mechanical ventilation it helps to avoid re-intubation and failure of weaning. The most important significant predictors of NIV outcome are NIV duration and body weight.
\end{abstract}

Keywords: Weaning, Intubation, Ventilation.

\section{INTRODUCTION}

Respiratory failure is one of the main reasons for admission to the pediatric intensive care unit (PICU). Children require invasive mechanical ventilation (IMV) as part of a therapeutic approach, which, despite allowing to modify the prognosis, involves lifethreatening complications that extend the length of stay in the hospital ${ }^{(\mathbf{1})}$.Post-extubation respiratory failure is also a common complication that remarkably increases morbidity and mortality. The rate of extubation failure among children ranges from $3 \%$ to $22 \%{ }^{(2)}$.

The ability to avoid endotracheal intubation by using Non-invasive ventilation (NIV) means that the upper airway remains intact and both physiological functions and airway defense mechanisms are preserved. Some controlled studies and meta-analysis have shown its efficiency in adults, but experience in the pediatric population is limited. Despite this, NIV is frequently used in pediatric intensive care units (PICUs) to avoid intubation and prevent reintubation ${ }^{(3)}$.

NIV is a safe and effective means of improving gas exchange in patients with many types of acute respiratory failure. In patients with various forms of acute hypoxemic respiratory failure (pneumonia, congestive heart failure, chest-wall impairment, and so forth), this therapy slightly decreased the rate of intubation and improved survival ${ }^{(4)}$.

NIV has gained impetus as a ventilatory support therapy for pediatric patients. Its administration reduces the use of accessory muscles, heart rate, and respiratory rate. The main advantage of NIV is that it prevents invasive mechanical ventilation (IMV) and, therefore, any associated risk ${ }^{(5)}$.

The use of non-invasive ventilation as the firstline mode of mechanical ventilation in critically ill children admitted to PICUs may be associated with significant clinical benefits. Further high-quality evidence regarding optimal patient selection and timing of initiation of non-invasive ventilation could lead to less variability in clinical care between institutions and improved patient outcomes ${ }^{(\boldsymbol{(})}$. Hence this study aimed at evaluating the efficacy, identifying possible predictors for the success of NIV in preventing intubation and re-intubation, and also determining the characteristics, and outcomes associated with NIV therapy in PICUs settings.

\section{SUBJECTS AND METHODS}

The present Clinical Trial study was conducted at the Pediatric Intensive Care Units, Children Hospital, Zagazig, and Al-Ahrar University Hospitals. The study 
included sixty patients admitted in the intensive care units in the period from July 2018 to March 2019.

Sample size: Assuming that $\mathrm{FiO}_{2}$ after 2 hours in NIV as a first-line treatment group is $0.54 \pm 0.25$ vs $0.38 \pm 0.18$ in the post-extubation group. So, the sample was calculated to be 60 cases (30 Cases in each group) by using OPEN-EPI at CI 95\% and Power $80 \%$.

\section{Ethical Considerations:}

The study was approved by the Ethics Board of Zagazig University and an informed written consent was taken from each participant in the study.

\section{Inclusion criteria:}

Eligible patients aged between $>1$ month and $<16$ years fall into one of two groups; Group (A): (first-line treatment), Group (B): (post-extubation). The patients are subdivided into failure subgroup if tracheal intubation or reintubation occur and success subgroup if tracheal intubation or reintubation is avoided.

\section{Exclusion criteria:}

Required immediate intubation due to severe hypoxia, acidosis, upper airway obstruction, recurrent apneas, or cardio-pulmonary arrest. Had a tracheostomy in place. Had pneumothorax or pneumomediastinum. Had facial anomalies (unrepaired cleft palate, choanal atresia) or had recent craniofacial surgery. Were reintubated for subsequent surgery, radiological or interventional procedure. Had been previously recruited to the study during the same PICU admission.

All patients were subjected to; Complete history taking (age, gender, the primary reason for PICU admission, PIM-2 score). Complete clinical examination. ICU events.

\section{Criteria of weaning from mechanical ventilation:}

We screened patients with respiratory failure receiving MV for more than $48 \mathrm{~h}$, who had been admitted to the PICU and who met the criteria for weaning from MV traditionally used in the PICU routine for improvement or resolution of the cause of respiratory failure: adequate gas exchange indicated by $\mathrm{PaO}_{2} / \mathrm{FiO}_{2} \geq 200$ or $\mathrm{PaO}_{2}>60 \mathrm{mmHg}, \mathrm{SpO}_{2} \geq 90 \%$ at a $\mathrm{FiO}_{2} \leq 0.40$, with a PEEP $\leq 5 \mathrm{cmH} 2 \mathrm{O}$; Glasgow Coma Scale $\geq 11$; body temperature $\leq 38 \mathrm{C}$; hemoglobin level $>10 \mathrm{~g} / \mathrm{dl}$; physiological measurements of respiratory rate $(f) \leq 35 \mathrm{bpm}$, tidal volume (VT) in spontaneous breathing $>5 \mathrm{~mL} / \mathrm{kg}$, negative inspiratory force $\leq 20-25 \quad \mathrm{cmH} 2 \mathrm{O}$; hemodynamic stability with no vasoactive drugs (dopamine, dobutamine or noradrenaline) and no sedative agents as described elsewhere.

\section{Weaning parameters:}

Before the beginning of the protocol, the traditional weaning parameters were measured, rate (f), tidal volume (VT), minute ventilation (VE), and rapid shallow breathing index (f/VT). During TT ventilation, VT and VE were measured using a respirometer. The decision for weaning or extubation was determined by the intensive care physician who was blinded to the study design.

\section{NIV technique:}

Continuous positive airway pressure (CPAP) was used (underwater seal CPAP) which was provided by nasal prongs or nasal mask. the orogastric tube was placed in all patients before initiation of CPAP therapy to prevent gastric distention. A protective patch was put over the skin of the nasal bridge in a tight-fitting nasal mask to prevent skin breakdown. Initial setting and further adjustment of CPAP parameters done according to age, clinical status, follow up of arterial blood gases as a baseline, follow up after $2 \mathrm{~h}, 6 \mathrm{~h}, 12 \mathrm{~h}, 24 \mathrm{~h}$, and $48 \mathrm{~h}$.

\section{Tracheal intubation or reintubation criteria in pediatric patients:}

- Cardiac or respiratory arrest,

- Agitation is not adequately controlled by sedation.

- Respiratory pauses with loss of consciousness or gasping for air.

- Massive aspiration.

- Persistent inability to remove respiratory secretions.

- Heart rate (HR) below 50 beats/min with loss of alertness.

- Hemodynamic instability with no response to fluids and vasoactive drugs.

\section{PIM-2 score:}

PIM-2 score is a scoring system for rating the severity of medical illness for children, one of several ICU scoring systems. Its name stands for "Pediatric Index of Mortality". It has been designed to provide predicted mortality for a patient by following a well-defined procedure. Predicted mortalities are good when dealing with several patients because the average predicted mortality for a group of patients is an indicator of the morbidity of these patients.

\section{Statistical analysis}

Data analysis was performed using the software SPSS (Statistical Package for the Social Sciences) version 20. Quantitative variables were described using their means and standard deviations.

Categorical variables were described using their absolute frequencies and to compare the proportion of categorical data, the Chi-square test, and Fisher exact tests were used when appropriate. 
Kolmogorov-Smirnov (distribution-type) and Levene (homogeneity of variances) tests were used to verify assumptions for use in parametric tests. To compare the means of the two groups, Mann Whitney test (for not normally distributed data) was used. Binary logistic regression analysis was used to calculate the odds of certain risk factors in producing the outcome. The level of statistical significance was set at $5 \%(P<0.05)$. A highly significant difference was present if $\mathrm{p} \leq 0.001$.

\section{RESULTS}

Half of the studied patients who had NIV as the firstline treatment were males with a median age of 10.5 months ranging from 2 to 132 months. Median body weight was $8.15 \mathrm{~kg}$ ranging from 3.5 to $41 \mathrm{~kg}$ (Table 1). Sixty percent of the studied patients who had NIV after extubation were males with a median age of 10 months ranging from 2 to 168 months. Median body weight was $8.35 \mathrm{~kg}$ ranging from 3.4 to $58 \mathrm{~kg}$ (Table 1 ).

About $77 \%$ and $50 \%$ of the studied patients wither NIV as the first line or after extubation had underlying diagnosis related to the respiratory system (Table 2).

Half of the studied patients had NIV as the first line of treatment as a result of cyanosis, while slightly more than of them were ventilated due to respiratory distress grade IV (Table 3). Among group (B); seventy threequarters percent were ventilated due to respiratory distress grade IV and $40 \%$ had cyanosis as a cause of ventilation (Table 3 ).
Concerning the outcome of patients within group A; one-sixth of the studied patients had failed weaning trials, and two patients had died by the end of the study. Within-group B; one-fifth of the studied patients had failed weaning trials, and only one patient (3.3\%) had died by the end of the study (Table 4).

There is a statistically significant difference between the outcome of weaning among group A and all of PIM-2 score, PIM-2 percent, and NIV duration. Patients, with lower PIM-2 percent and prolonged NIV duration, had successful weaning. On the other hand, there is a statistically non-significant relation between the outcome of weaning and either gender, PIM-age, body weight, or length of PICU stay (Table 5a).

There is a statistically significant difference between the outcome of weaning among group B and all of the patients' age, body weight, and NIV duration. Older patients, with higher body weight and prolonged NIV duration, had successful weaning. On the other hand, there is a statistically non-significant relation between the outcome of weaning and either gender, PIM-2 score, PIM-2 percent, PICU stays, or duration of mechanical ventilation (Table $5 b$ ).

Among all the studied factors showed significant association with the fate of weaning in group A, only increasing NIV duration significantly predict weaning success (OR 4.394, p<0.05) (Table 6). While only increasing body weight predicts weaning success (OR 1.613) (Table 6).

Table (1): Distribution of the studied patients according to demographic characteristics and their body weight.

\begin{tabular}{|c|c|c|}
\hline \multirow{2}{*}{ Variables } & First-line & After extubation \\
\cline { 2 - 3 } Gender: & $\mathbf{N}(\%)$ & $\mathbf{N}(\%)$ \\
Male & $15(50)$ & $18(60)$ \\
Female & $15(50)$ & $12(40)$ \\
\hline Age: & $24 \pm 31.95$ & $16.93 \pm 30.74$ \\
Mean \pm SD & $10.5(2-132)$ & $10(2-168)$ \\
Median (range) & $10.71 \pm 7.9$ & \\
Body weight (kg): & $8.15(3.5-41)$ & $8.69 \pm 9.71$ \\
Mean \pm SD & \multicolumn{2}{|c}{} \\
Median (range) & & \\
\hline
\end{tabular}

Table (2): Distribution of the studied patients regarding underlying diagnosis.

\begin{tabular}{|l|c|c|}
\hline & First-line & After extubation \\
\hline & $\mathbf{N}(\%)$ & $\mathbf{N}(\%)$ \\
\hline Diagnosis: & $23(76.7)$ & $15(50)$ \\
Respiratory & $4(13.3)$ & $6(20)$ \\
Neurological & $2(6.7)$ & $1(3.3)$ \\
Cardiac & $1(3.3)$ & $2(6.7)$ \\
Sepsis & $1(3.3)$ & $0(0)$ \\
GI causes & $0(0)$ & $1(3.3)$ \\
Renal & $1(3.3)$ & $1(3.3)$ \\
Endocrinological & $0(0)$ & $1(3.3)$ \\
Blood diseases & \multicolumn{2}{|}{} \\
\hline
\end{tabular}


Table (3): Distribution of the studied patients regarding the cause of ventilation.

\begin{tabular}{|l|c|c|}
\hline & First-line & After extubation \\
\hline Cause: & $\mathbf{N}=\mathbf{3 0}(\boldsymbol{\%})$ & $\mathbf{N}=\mathbf{3 0}(\mathbf{\%})$ \\
Apnea & & \\
Cyanosis & $1(3.3)$ & $3(10)$ \\
Fits & $7(50)$ & $12(40)$ \\
Disturbed consciousness & $2(6.7)$ & $5(13.3)$ \\
Dehydration & $2(6.7)$ & $1(3.3)$ \\
RD IV & $1(3.3)$ & $0(0)$ \\
Stridor & $23(76.7)$ & $21(70)$ \\
& $0(0)$ & $2(6.7)$ \\
\hline
\end{tabular}

Table (4): Distribution of the studied patients regarding the outcome of weaning and mortality.

\begin{tabular}{|c|c|c|}
\hline \multirow{2}{*}{ Parameter } & First-line & After extubation \\
\cline { 2 - 3 } & $\mathbf{N}(\boldsymbol{\%})$ & $\mathbf{N}(\boldsymbol{\%})$ \\
\hline Weaning: & $5(16.7)$ & $6(20)$ \\
Failure & $25(83.3)$ & $24(80)$ \\
Success & $2(6.7)$ & $1(3.3)$ \\
\hline Mortality: & $28(93.3)$ & $29(96.7)$ \\
Died & \\
Survived &
\end{tabular}

Table (5a): Relation between weaning outcome and all of the Demographic Characteristics, Body Weight, Length of Stay and Outcome among patients who had NIV as the first line of treatment (Group A).

\begin{tabular}{|c|c|c|c|c|}
\hline 2. & \multicolumn{2}{|c|}{ Outcome } & \multirow{2}{*}{ Test } & \multirow[t]{2}{*}{ P-value } \\
\hline & $\begin{array}{c}\text { Failed } \\
\mathrm{N}=6(\%)\end{array}$ & $\begin{array}{l}\text { Successful } \\
\mathrm{N}=24(\%)\end{array}$ & & \\
\hline $\begin{array}{c}\text { Gender : } \\
\text { Male } \\
\text { Female } \\
\end{array}$ & $\begin{array}{l}1(16.7) \\
5(83.3) \\
\end{array}$ & $\begin{array}{l}14(58.3) \\
10(41.7)\end{array}$ & Fisher & 0.169 \\
\hline $\begin{array}{c}\text { Age }(\mathbf{M}): \\
\quad \text { Mean } \pm \text { SD } \\
\text { Median }\end{array}$ & $\begin{array}{c}43.83 \pm 49.84 \\
25\end{array}$ & $\begin{array}{c}19.04 \pm 24.88 \\
10\end{array}$ & $\begin{array}{c}\mathrm{Z} \\
-1.272\end{array}$ & 0.204 \\
\hline $\begin{array}{c}\text { Weight }(\mathrm{Kg}): \\
\text { Mean } \pm \text { SD } \\
\text { Median }\end{array}$ & $\begin{array}{c}15.5 \pm 13.35 \\
11.5\end{array}$ & $\begin{array}{c}9.51 \pm 5.69 \\
7.95\end{array}$ & $\begin{array}{c}\mathrm{Z} \\
-1.115 \\
\end{array}$ & 0.265 \\
\hline $\begin{array}{l}\text { PIM-2 score : } \\
\text { Mean } \pm \text { SD } \\
\text { Median }\end{array}$ & $\begin{array}{c}-2.26 \pm 0.74 \\
-1.87\end{array}$ & $\begin{array}{c}-2.82 \pm 1.67 \\
-3.03 \\
\end{array}$ & $\begin{array}{c}Z \\
\mathbf{- 1 . 9 7}\end{array}$ & $0.049 *$ \\
\hline $\begin{array}{c}\text { PIM-2 percent : } \\
\text { Mean } \pm \text { SD } \\
\text { Median } \\
\end{array}$ & $\begin{array}{c}10.7 \pm 5.17 \\
13.35\end{array}$ & $\begin{array}{c}4.89 \pm 2.98 \\
4.45\end{array}$ & $\begin{array}{c}Z \\
-2.385 \\
\end{array}$ & $0.017 *$ \\
\hline $\begin{array}{c}\text { PICU stay (D) : } \\
\text { Mean } \pm \text { SD } \\
\text { Median } \\
\end{array}$ & $\begin{array}{c}24.67 \pm 8.55 \\
25\end{array}$ & $\begin{array}{c}19.88 \pm 8.32 \\
19\end{array}$ & $\begin{array}{c}\mathrm{Z} \\
-1.271 \\
\end{array}$ & 0.204 \\
\hline $\begin{array}{c}\text { NIV duration }(\mathbf{D}) \\
\text { Mean } \pm \text { SD } \\
\text { Median }\end{array}$ & $\begin{array}{c}2.33 \pm 0.52 \\
2\end{array}$ & $\begin{array}{c}6.21 \pm 3.28 \\
6\end{array}$ & $\begin{array}{c}Z \\
-3.09\end{array}$ & $0.002 *$ \\
\hline
\end{tabular}

$* p<0.05$ is statistically significant Z Mann Whitney test NIV Non-invasive ventilation D days PICU pediatric intensive care unit 
Table (5b): Relation between weaning outcome and all of the Demographic Characteristics, Body Weight, Length of Stay, and Outcome among patients who had NIV after Extubation (Group B).

\begin{tabular}{|c|c|c|c|c|}
\hline & \multicolumn{2}{|c|}{ Outcome of weaning } & \multirow{3}{*}{ Test } & \multirow{3}{*}{ p-value } \\
\hline & Failed & Successful & & \\
\hline & $\mathrm{N}=5(\%)$ & $\mathrm{N}=25(\%)$ & & \\
\hline $\begin{array}{c}\text { Fender: } \\
\text { Male } \\
\text { Female }\end{array}$ & $\begin{array}{l}3(60) \\
2(40)\end{array}$ & $\begin{array}{l}15(60) \\
10(40)\end{array}$ & Fisher & $>0.999$ \\
\hline \begin{tabular}{|c|} 
ge $(\mathbf{M}):$ \\
$\quad$ Mean \pm SD \\
Median \\
\end{tabular} & $\begin{array}{c}5 \pm 2.12 \\
5\end{array}$ & $\begin{array}{c}19.32 \pm 33.24 \\
12\end{array}$ & $\begin{array}{c}Z \\
-2.063\end{array}$ & 0.039* \\
\hline \begin{tabular}{|c|} 
Neight $(\mathbf{K g})$ : \\
Mean \pm SD \\
Median \\
\end{tabular} & $\begin{array}{c}5.34 \pm 1.99 \\
4.2 \\
\end{array}$ & $\begin{array}{c}10.56 \pm 10.42 \\
8.8 \\
\end{array}$ & $\begin{array}{c}Z \\
-2.282 \\
\end{array}$ & $0.022 *$ \\
\hline $\begin{array}{c}\text { IM-2 score: } \\
\text { Mean } \pm \text { SD } \\
\text { Median }\end{array}$ & $\begin{array}{c}-2.75 \pm 0.35 \\
-2.95\end{array}$ & $\begin{array}{c}-3 \pm 0.81 \\
-2.88\end{array}$ & $\begin{array}{c}Z \\
-0.473\end{array}$ & 0.636 \\
\hline $\begin{array}{c}\text { IM-2 percent: } \\
\text { Mean } \pm \text { SD } \\
\text { Median } \\
\end{array}$ & $\begin{array}{c}6.24 \pm 2.14 \\
5\end{array}$ & $\begin{array}{c}5.99 \pm 4.09 \\
5.3 \\
\end{array}$ & $\begin{array}{c}Z \\
-0.445 \\
\end{array}$ & 0.656 \\
\hline $\begin{array}{c}\text { ICU stay (D): } \\
\text { Mean } \pm \text { SD } \\
\text { Median }\end{array}$ & $\begin{array}{c}37.8 \pm 18.43 \\
43\end{array}$ & $\begin{array}{c}23.88 \pm 8.52 \\
24\end{array}$ & $\begin{array}{c}Z \\
-1.364 \\
\end{array}$ & 0.173 \\
\hline $\begin{array}{l}\text { NIV duration }(\mathbf{D}) \text { : } \\
\text { Mean } \pm \text { SD } \\
\text { Median }\end{array}$ & $\begin{array}{c}2.2 \pm 0.45 \\
2\end{array}$ & $\begin{array}{c}4.2 \pm 1.8 \\
4\end{array}$ & $\begin{array}{c}Z \\
-2.675\end{array}$ & $0.007 *$ \\
\hline $\begin{array}{l}\text { MV duration }(\mathbf{D}): \\
\text { Mean } \pm \text { SD } \\
\text { Median }\end{array}$ & $\begin{array}{c}13.32 \pm 8.98 \\
9\end{array}$ & $\begin{array}{c}8.6 \pm 4.16 \\
10\end{array}$ & $\begin{array}{c}Z \\
-1.59\end{array}$ & 0.112 \\
\hline
\end{tabular}

* $p<0.05$ is statistically significant Z Mann Whitney test NIV Non-invasive ventilation MV mechanical ventilation $\mathrm{D}$ days PICU pediatric intensive care unit

Table (6): Logistic regression of variables significantly associated with weaning success in patients who received NIV as the first line and used after extubation.

\begin{tabular}{|l|c|c|c|c|}
\hline & \multirow{2}{*}{ AOR } & \multicolumn{2}{|c|}{ 95\% CI } & \multirow{2}{*}{ p-value } \\
\cline { 3 - 4 } & & Lower & Upper & \\
\hline NIV duration & 4.394 & 1.096 & 15.547 & $0.036^{*}$ \\
\hline Weight (kg) & 1.613 & 0.999 & 2.604 & 0.05 \\
\hline
\end{tabular}

AOR adjusted odds ratio $\quad \mathrm{CI}$ confidence interval $* \mathrm{p}<0.05$ is statistically significant

\section{DISCUSSION}

In the current study, the success rate in patients receiving NIV as the first line of treatment was $80 \%$. This agreed with Fedor ${ }^{(7)}$ and Bonora et al. ${ }^{\left({ }^{(8)}\right.}$ who found that the overall success rate was $77.5 \%$, and $72.7 \%$ respectively. In a similar group of patients, Javouhey et al. ${ }^{(9)}$ reported the success rate was $81 \%$ in their retrospective study using NIV as primary ventilatory support. Essouri et al. ${ }^{(10)}$ illustrated an overall success rate of $77 \%$ in a 5-year observational study, where 114 children with different causes of respiratory failure receiving NIV as the first-line treatment. Abadesso et al. (11) also found that $77.5 \%$ were successfully treated with NIV as the first-line treatment and $22.5 \%$ of children needed invasive ventilation (due to NIV failure). James et al. ${ }^{(3)}$ found that NIV as the first-line treatment was successful in 53 $(64 \%)$ cases and unsuccessful in $30(36 \%)$ cases.
Success rates may differ from one study to another because of the heterogeneity of the groups being studied, age, and diagnosis. Considering the PIM-2 score, there was a statistically significant difference between failed and successful subgroups within the first-line treatment (higher in the failed subgroup and lower in the successful subgroup). Abadesso et al. ${ }^{(11)}$ found that the PIM-2 score was higher in the failed subgroup. But this disagrees with Bernet et al. ${ }^{(12)}$ who did not find differences in PIM-2 score between patients managed successfully and unsuccessfully on NIV. Also, James et al. (3) similarly, found that there was no difference in PIM-2 scores between successful and failed subgroups within the first-line treatment.

The present study showed a statistically significant difference in NIV duration (days) between failed (2.33 $\pm 0.52)$ and successful $(6.21 \pm 3.28)$ subgroups within the first-line treatment as it was less duration in the failed subgroup and more duration in the successful 
subgroup. This agreed with Abadesso et al. ${ }^{(11)}$. This is logic as we abort the NIV trial secondary to worsening of the condition.

Among all the studied factors showed significant association with the fate of NIV as the first line of treatment, only increasing NIV duration significantly predict NIV success (OR 4.394, $\mathrm{p}<0.05)$.

The present study reported a statistically nonsignificant difference between the failed subgroup and successful subgroup regarding demographic data and PICU length of stay. Several studies demonstrate the same statistical relation ${ }^{(3,11)}$.

In our study, the mortality rate in patients who had NIV as the first-line treatment was $3.3 \%$. This agrees with Morris et al. ${ }^{(13)}$ who found that the mortality rate was $4.4 \%$. Also, Garpestad et al. ${ }^{\text {(14) }}$ found that NIV is associated with an improvement in respiratory status and a reduction in the length of stay in the intensive care unit, and in mortality. Among all the studied factors showed significant association with the fate of NIV as the first line of treatment, only increasing NIV duration significantly predict NIV success (OR 4.394, $\mathrm{p}<0.05)$.

Regarding studied patients connected to NIV after extubation, it was found that half of them had underlying diagnosis related to the respiratory system. This agreed with James et al. ${ }^{(3)}$ who found that the respiratory system was the underlying diagnosis only in $41.3 \%$ of cases

In the current study, the success rate of weaning from MV who plotted to NIV was $83.3 \%$. In a prospective observational study that included 41 postextubation NIV episodes, the global NIV success was $65.9 \%{ }^{(15)}$. Also, James et al. ${ }^{(3)}$ reached a $90 \%$ success rate with NIV in children who were in the immediate postoperative period. Also, Gupta et al. ${ }^{(16)}$ allocated patients to receive NIV if they were at high risk for extubation failure and if they were weaning from IMV and achieved a success rate of $74 \%$. Also, Mayordomo-Colunga et al. ${ }^{(15)}$ and Bonora et al. ${ }^{(8)}$ conveyed that the success of NIV was around $70 \%$.

Talking about our studied patients connected to NIV after extubation, half of them had underlying diagnosis related to the respiratory system. Forty percent of the studied patients had been ventilated as a result of cyanosis, while $70 \%$ of them were ventilated due to respiratory distress grade IV. This agrees with James et al. ${ }^{(3)}$ who found that the respiratory system was the underlying diagnosis only in $41.3 \%$ of cases.

In the current study, the success rate of weaning from MV who plotted to NIV was $83.3 \%$. In a prospective observational study that included 41 postextubation NIV episodes, the global NIV success was $65.9 \%{ }^{(15)}$. Also, James et al. ${ }^{(3)}$ reported a $90 \%$ success rate with NIV in children who were in the immediate postoperative period. Also, Gupta et al. ${ }^{(16)}$ allocated patients to receive NIV if they were at high risk for extubation failure and if they were weaning from IMV and achieved a success rate of $74 \%$. Also, Mayordomo-Colunga et al. ${ }^{(15)}$ and Bonora et al. ${ }^{(8)}$ found that the success of NIV was $72.7 \%$, which was similar to that observed in comparable studies.

Demographic statistics concerning outcome and fate of NIV showed statistically significant differences regarding age, body weight, and NIV duration (lower in the failed subgroup and higher in the successful subgroup). This agreed with Bonora et al. ${ }^{(8)}$ who found a direct association was observed between the hours of NIV and therapeutic success. This evidences that patients with successful NIV remained more hours in NIV but had a shorter stay in the PICU. But this disagrees with James et al. ${ }^{(3)}$ and Bonora et al. ${ }^{\left({ }^{(8)}\right.}$ who found that there was no significant difference between failed and successful subgroups regarding age. This difference with our study concerning age may be due to the small sample size of our study.

ICU mortality was more in the failure subgroup. This agreed with the study of Gupta et al. ${ }^{(16)}$ who found that the failure group had higher ICU mortality. Also, this agrees with the study of Nava et al. ${ }^{(18)}$ who found that the need for re-intubation is associated with a high risk of ICU mortality, use of NIV was associated with reduced risk of ICU mortality mediated by a decrease in the need of re-intubation. Similarly, Bonora et al. ${ }^{(8)}$ found that the failure subgroup had higher ICU mortality with no mortality rate in the successful subgroup. A meta-analysis by Burns et al. (19) evaluated the use of NIV as an alternate modality to help early weaning, observing that this strategy was associated with a significant reduction in mortality, the incidence of pneumonia, and MV duration.

Among all the studied factors showed significant association with the fate of weaning, only increasing body weight predicts weaning success (OR 1.613).

The main pearl of our study that NIV eliminates several risks associated with intubation such as upper airway trauma, post-extubation vocal cord dysfunction, requirement for heavy sedation, and ventilatorassociated complications such as pneumonia, barotrauma, or volutrauma. NIV reduces the rate of endotracheal intubation or re-intubation and thus reduces the morbidity and mortality associated with mechanical ventilation.

The study had many strong points, including being a prospective study. Yet it still had many limitations as lacking a control group. The study was done on a relatively small sample size in one center. Further large-scale multicenter studies are recommended to verify our findings regarding NIV.

\section{CONCLUSION}

Non-invasive ventilation as the first line of treatment in acute respiratory failure provides significant avoidance of intubation and lowers the incidence and risk of complications. Non-invasive ventilation if considered after weaning of invasive 
mechanical ventilation it helps to avoid re-intubation and failure of weaning. The most important significant predictors of NIV outcome are NIV duration and body weight.

\section{REFERENCES}

1. Piastra M, Picconi E, Morena T et al. (2019): Weaning of children with burn injury by noninvasive ventilation (NIV): a clinical experience. Journal of Burn Care \& Research, 40(5): 689-695.

2. Bach J (2017): Noninvasive respiratory management of patients with neuromuscular disease. Annals of Rehabilitation Medicine, 41(4): 519-525.

3. James C, Hallewell C, James D et al. (2011): Predicting the success of non-invasive ventilation in preventing intubation and re-intubation in the pediatric intensive care unit. Intensive Care Medicine, 37(12): 1994-2001.

4. Antonelli M, Conti G, Pennisi M (2000): Noninvasive ventilation in intensive care. Minerva Anestesiol., 66(12):867-74.

5. Regunath H, Whitacre T, Whitt $S$ (2018): Noninvasive Ventilation in Neuro Muscular Diseases. In Sleep Issues in Neuromuscular Disorders. Springer, Cham, Pp. 129-138.

6. Morris J, Padmanabhan R, Roger C et al. (2017): Outcomes for Children Receiving Non-invasive Ventilation as the First-Line Mode of Mechanical Ventilation at Intensive Care Admission: A Propensity Score-Matched Cohort Study. Crit Care Med., 45(6): 1045-1053.

7. Fedor K (2017): Noninvasive respiratory support in infants and children. Respiratory Care, 62(6): 699-717.

8. Bonora J, Frydman J, Retta A et al. (2018): Postextubation non-invasive ventilation in the pediatric intensive care unit: a multicenter study. Arch Argent Pediatr., 116(5): 333-339.

9. Javouhey E, Barats A, Richard N (2008): Noninvasive ventilation as primary support for infants with severe bronchiolitis. Intensive Care Med., 34:160814
10. Essouri S, Chevret L, Durand P (2006): Noninvasive positive pressure ventilation: five years of experience in a pediatric intensive care unit. Pediatr Crit Care Med., 7:329-334

11. Abadesso C, Nunes P, Silvestre C (2012): Noninvasive ventilation in acute respiratory failure in children. Pediatric Reports, 4(2): 10-16.

12. Bernet V, Hug M, Frey B (2005): Predictive factors for the success of noninvasive mask ventilation in infants and children with acute respiratory failure. Pediatr Crit Care Med., 6:660-664.

13. Morris J, Ramnarayan P, Parslow R (2017): Outcomes for children receiving noninvasive ventilation as the first-line mode of mechanical ventilation at intensive care admission: A propensity score-matched cohort study. Critical Care Medicine, 45(6): 1045-55.

14. Garpestad E, Brennan J, Hill N (2007): Noninvasive ventilation for Critical Care. Chest, 132:711-20.

15. Mayordomo-Colunga J, Medina A, Rey C (2009): Predictive factors of non-invasive ventilation failure in critically ill children: a prospective epidemiological study. Intensive Care Med., 35:527-536.

16. Gupta N, Finlay G, Kotloff $R$ et al. (2017): Lymphangioleiomyomatosis diagnosis and management: high-resolution chest computed tomography, transbronchial lung biopsy, and pleural disease management. An Official American Thoracic Society/Japanese Respiratory Society Clinical Practice Guideline. American Journal of Respiratory and Critical Care Medicine, 196(10): 1337-1348.

17. Bonora J, Frachia D, García M et al. (2011): Ventilación no invasiva en cuidado Intensivo Pediátrico, cuatro años de experiencia. Archivos argentinos de pediatría, 109(2): 124-128.

18. Nava S, Gregoretti C, Fanfulla $F$ et al. (2005): Noninvasive ventilation to prevent respiratory failure after extubation in high-risk patients. Crit Care Med., 33:2465-70.

19. Burns K, Adhikari N, Meade M (2006): A metaanalysis of noninvasive weaning to facilitate liberation from mechanical ventilation. Can J Anaesth., 53:30515. 